\title{
Effect of Early Administration of Vitamin D on Clinical Outcome in Critically Ill Sepsis Patients: A Randomized Placebo-controlled Trial
}

\author{
Amrita Bhattacharyya $^{1} \odot$, Rajeshwari Subramaniam², Dalim K Baidya ${ }^{3} \odot$, Praveen Aggarwal ${ }^{4} \odot$, Naveet $^{2}$ Wig $^{5} \odot$
}

\begin{abstract}
Background: Administration of vitamin D to unselected heterogeneous critically ill patients did not demonstrate outcome benefit. The current study was undertaken to identify if early administration of vitamin D can reduce intensive care unit (ICU) length of stay and improve clinical outcomes in critically ill patients with sepsis.

Methods: This single-center randomized double-blind placebo-controlled trial was done in the ICU and emergency inpatient ward of a tertiary care teaching institute in New Delhi, India. A total of 126 adult patients aged 18 to 80 years of either sex diagnosed to have sepsis were included within 24 hours of admission to the hospital and randomized into vitamin D or placebo groups. The patients in the intervention group received vitamin D3 540,000 units dissolved in $45 \mathrm{~mL}$ of milk. The placebo group received $45 \mathrm{~mL}$ of milk.

Results: The median length of ICU stay ( 8 vs 9 days; $p=0.32$ ), median length of hospital stay (12 vs 12 days; $p=0.33$ ), median duration of vasopressors requirement ( 4 vs 3 days; $p=0.84$ ), median duration of mechanical ventilation ( 5 vs 7 days; $p=0.23$ ), requirement of tracheostomy (34 vs 39\%; $p=0.71$ ), and 90-day mortality [35 vs 46\%; $p=0.29 ; \mathrm{HR} 0.72(0.42-1.24)$ ] were similar in vitamin D and placebo arm.

A subgroup analysis in patients with severe vitamin $D$ deficiency (vitamin $D<12 \mathrm{ng} / \mathrm{mL}$ ) revealed a significantly decreased incidence of tracheostomy ( 28 vs $57 \% ; p=0.04$ ), a trend toward decreased 90 -day mortality [34 vs $66 \% ; p=0.08 ;$ HR $0.44(0.19-1.01)$ ], and duration of mechanical ventilation ( 6 vs 11 days; $p=0.05$ ) in patients receiving vitamin $D$.

Conclusion: Administration of large-dose vitamin D within 24 hours of admission does not reduce the length of ICU stay in critically ill sepsis patients.

Keywords: Intensive care unit outcomes, Sepsis, Vitamin D.

Indian Journal of Critical Care Medicine (2021): 10.5005/jp-journals-10071-23993
\end{abstract}

\section{INTRODUCTION}

Most cells of the body including the immunoregulatory cells have vitamin $D$ receptors (VDR), as well as the enzymes responsible for hydroxylation and activation of vitamin D. ' Vitamin D regulates gene expression, cellular proliferation, differentiation, and apoptosis in various tissues. ${ }^{2}$ It also influences the production and differentiation of $\mathrm{T}$ and $\mathrm{B}$ cells and modulates immunoglobulin production. ${ }^{3}$ Vitamin D deficiency is common in critically ill patients with sepsis and has been associated with increased mortality. ${ }^{4}$ However, it is still unclear whether vitamin D supplementation can improve clinical outcomes. Although a few large randomized controlled trials (RCTs) in heterogeneous intensive care unit (ICU) patients failed to demonstrate any clinical benefit of administration of vitamin D, early supplementation of vitamin D appears to have a sound theoretical basis, especially in the vulnerable sepsis subpopulation. ${ }^{5,6}$ This study was planned to identify if early administration of vitamin D can reduce ICU length of stay and improve clinical outcomes in critically ill patients with sepsis.

\section{Methods}

\section{Study Design and Setting}

This single-center randomized double-blind placebo-controlled trial was performed in the intensive care unit and emergency inpatient ward of a tertiary care teaching institute in New Delhi, India.

\begin{abstract}
${ }^{1}$ Department of Critical Care Medicine, Calcutta Medical Research Institute, Kolkata, West Bengal, India

2,3 Department of Anesthesiology, Pain Medicine and Critical Care, All India Institute of Medical Sciences, Delhi, India

${ }^{4}$ Department of Emergency Medicine, All India Institute of Medical Sciences, Delhi, India

${ }^{5}$ Department of Medicine, All India Institute of Medical Sciences, Delhi, India

Corresponding Author: Dalim K Baidya, Department of Anesthesiology, Pain Medicine and Critical Care, All India Institute of Medical Sciences, Delhi, India, e-mail: dalimkumar.ab8@gmail.com

How to cite this article: Bhattacharyya A, Subramaniam R, Baidya DK, Aggarwal P, Wig N. Effect of Early Administration of Vitamin D on Clinical Outcome in Critically III Sepsis Patients: A Randomized Placebo-controlled Trial. Indian J Crit Care Med 2021;25(10):1147-1154.
\end{abstract}

Source of support: Nil

Conflict of interest: None

\section{Ethics Approval and Trial Registration}

Institute ethics committee approval was obtained (IECPG239/28.09.2018, RT-39/30.08.2018), and the study protocol was registered in the clinical trial registry of India (www.ctri.nic.in; Reference number CTRI/2019/12/022537).

(C) The Author(s). 2021 Open Access This article is distributed under the terms of the Creative Commons Attribution 4.0 International License (https://creativecommons. org/licenses/by-nc/4.0/), which permits unrestricted use, distribution, and non-commercial reproduction in any medium, provided you give appropriate credit to the original author(s) and the source, provide a link to the Creative Commons license, and indicate if changes were made. The Creative Commons Public Domain Dedication waiver (http://creativecommons.org/publicdomain/zero/1.0/) applies to the data made available in this article, unless otherwise stated. 


\section{Study Population}

All eligible adult patients aged 18 to 80 years of either sex diagnosed to have sepsis based on sepsis 3 definition ${ }^{5}$ were considered for inclusion in the study. Written informed consent was obtained from patients or legally acceptable representatives (LAR) before inclusion.

The following were the inclusion criteria: age 18 to 80 years, presented to the emergency department and expected to be admitted to the ICU and survive for more than 96 hours; meets criteria for the definition of sepsis in last 12 hours; enteral access in place; and able to tolerate enteral drug administration. Exclusion criteria were as follows: history of malabsorption syndromes; gastrointestinal intolerance (diarrhea, vomiting, or increased nasogastric aspirates); pregnancy or lactating mother; other trial participation; patients not deemed suitable for study participation (i.e., psychiatric disease, living remotely from the center, or prisoner status); hospice, or palliative care status; history of documented adverse reaction to vitamin D supplementation; renal stones/hypercalcemia within the past 1 year; baseline serum calcium $\geq 10.5 \mathrm{mg} / \mathrm{dL}$ or ionized calcium $>5.2 \mathrm{mg} / \mathrm{dL}$; established diagnosis of a medical condition associated with a high risk of hypercalcemia (e.g. metastatic cancer, sarcoidosis, multiple myeloma, primary hyperparathyroidism); history of therapy with high-dose vitamin D3 (greater than or equal to 50,000 IU/week) within previous 6 months; chronic maintenance dialysis, more than 24 hours of sepsis diagnosis; and allergy to dairy products.

\section{Randomization, Blinding, and Intervention}

A web-based randomization sequence was generated from http:// www.randomizer.org, and a randomization block of 6 was used to divide the population into intervention and placebo groups. The patients in the intervention group received vitamin D3 540,000 units dissolved in $45 \mathrm{~mL}$ of milk. The placebo group received $45 \mathrm{~mL}$ of milk. The treating physicians, investigators, and the patients remained blinded. The drug or placebo was prepared by a nurse involved in the clinical care of the patient in a separate room and administered to the patients in an identical opaque syringe. Drug or placebo was administered either orally or via enteral access. Randomization was performed within 24 hours of hospital presentation, and study/placebo was administered within 2 hours of randomization.

\section{Baseline and Outcomes Parameters}

Baseline parameters were (i) demographic and admission data (including age, sex, height, weight, body mass index); (ii) pertinent medical history; (iii) history of chronic cardiac or pulmonary illnesses; (iv) home vitamin D and calcium supplementation; and (v) pregnancy test for women of reproductive age, if not performed in routine clinical care.

The primary outcome was the ICU length of stay, and secondary outcomes were 90-day mortality, hospital length of stay, duration of mechanical ventilation, duration of vasopressor requirement, change in procalcitonin level from baseline to day 5 , change in sequential organ failure assessment (SOFA) score from baseline to day 5 , and change in $25-(\mathrm{OH})$-cholecalciferol level from baseline to day 5 assessed by chemiluminescence immunoassay.

Safety parameters were changed in calcium level from baseline to day 5 and assessment for kidney stones, fall-related fractures, and symptomatic hypercalcemia requiring treatment on the 90-day follow-up.

\section{Data Collection}

The treating team and data collection team for our study participants were separate and both teams along with the patients themselves were blinded. The data collection team collected relevant baseline data on study enrolment. Clinical outcome parameters were collected by daily chart review. Procalcitonin levels were assessed on day 1 and day 5 at the same point of care unit. Samples for 25-cholecalciferol were collected at baseline and day 5 and stored. These samples were analyzed at the end of the study. The post-discharge assessment was conducted by telephonic interview.

\section{Sample Size Estimation and Statistical Analysis}

As per the database of the past 2 years of sepsis patients in our ICU, the mean length of ICU stay was $10 \pm 4$ days. ${ }^{6}$ Considering a decrease in ICU stay of 2 days in the intervention group to be significant, the sample size calculated with a confidence interval of $95 \%, 80 \%$ power of the study and a 1:1 enrolment ratio for intervention and placebo was 126 with 63 in each group. Statistical analysis was performed using SPSS 26.0 (IBM Corp, USA) It was performed based on the intention to treat principle. There were $<1 \%$ missing data. Baseline demographic data were represented in mean and standard deviation. Outcomes like the length of ICU stay, length of hospital stay, duration of vasopressors, and duration of mechanical ventilation were compared using Mann-Whitney test and represented in median and range. We used a log-rank test to compare mortality at 90 days between the two arms. MannWhitney Tests were used to compare the SOFA score, vitamin D levels, calcium levels, and procalcitonin levels at baseline and day 5 . The change from baseline to day 5 was calculated using paired $t$-tests. We did a further subgroup analysis for patients with severe vitamin D deficiency (vitamin D level $<12 \mathrm{ng} / \mathrm{mL}$ ). We constructed Kaplan-Meier survival analysis curves to evaluate the 90 -day survival in the intention to treat population and in the subgroups with and without severe vitamin D deficiency.

\section{Results}

\section{Baseline and Demographic Data}

We assessed 533 patients for trial eligibility. Three hundred and ninety-seven patients were excluded due to various reasons. Among them, 21 patients satisfied inclusion criteria but they were excluded as consent could not be obtained within 22 hours of admission due to patients not being fit to provide consent and nonavailability of attendants, and finally, 126 patients were randomized within 24 hours of presentation to the hospital (Flowchart 1). No patient was lost to follow-up, and all 126 patients were included in the primary analysis. The median time to randomization was 6 hours in the study. The vitamin $D$ and placebo arms were both similar in terms of demographic and baseline data (Table 1). The most common source of sepsis was hospital-acquired pneumonia (23.8\%) in the vitamin $\mathrm{D}$ group and abdominal sepsis in the placebo group (22.2\%).

\section{Outcome Parameters}

Median length of ICU stay was 8 days in the vitamin D arm and 9 days in the placebo arm $(p=0.32)$. Median length of hospital stay, median duration of vasopressors requirement, median duration of 


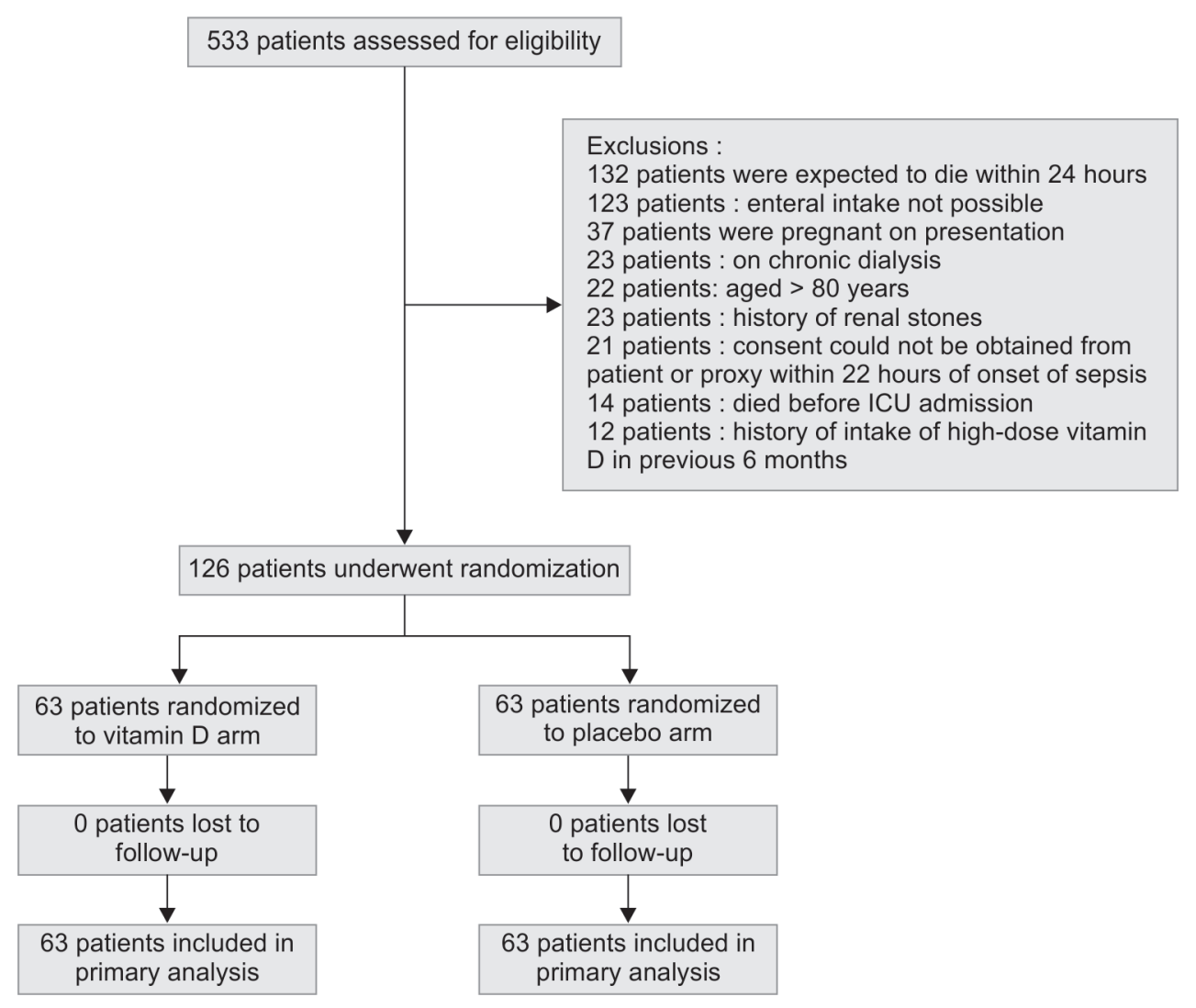

mechanical ventilation, requirement of tracheostomy, and 90-day mortality were not significantly different between the groups (Table 2).

We performed survival analysis of our study population using Kaplan-Meier curve (Fig. 1A). A subgroup analysis of outcome variables was performed in patients with severe vitamin $D$ deficiency (vitamin D levels $<12 \mathrm{ng} / \mathrm{mL}$ ) similar to VITdAL-ICU trial ${ }^{7}$ in view of literature evidence of increased rickets and osteomalacia in patients with vitamin $D<12 \mathrm{ng} / \mathrm{mL}$. In this subgroup, a significantly decreased incidence of tracheostomy, a trend toward decreased 90-day mortality and duration of mechanical ventilation, was observed in patients receiving vitamin D (Table 3 and Fig. 1B). However, there was no difference in outcomes between the treatment and placebo arm in the subgroup with mild/no vitamin D deficiency (vitamin D levels $\geq 12 \mathrm{ng} / \mathrm{mL}$; Table 3 and Fig. $1 \mathrm{C}$ ).

The SOFA scores were similar between the treatment and placebo arm on day $1(p=0.93)$ and day $5(p=0.80)$. There was a 33\% decrease in the SOFA score in the vitamin D arm and 20\% decrease in the placebo arm from day 1 to day 5 . The mean vitamin D level, as measured on admission, was $12.05 \mathrm{ng} / \mathrm{mL}$ in the vitamin D group and $15.47 \mathrm{ng} / \mathrm{mL}$ in the placebo $\operatorname{arm}(p=0.09)$. In the vitamin $D$ arm, on day 5 , the mean vitamin $D$ level rose to $17.73 \mathrm{ng} / \mathrm{mL}$ registering a $51 \%$ rise whereas the mean vitamin $\mathrm{D}$ level in the placebo group was 16.4 on day 5 with an increase of $5.26 \%$ (Table 4).

\section{Adverse Effects of Vitamin D}

Following ICU discharge, $13 \%$ of patients in the treatment group and $10 \%$ of patients in the placebo group continued to receive vitamin D supplementation. There was no report of fall-related fracture, kidney stones, or symptomatic hypercalcemia requiring treatment in the 90 days of follow-up.

\section{Discussion}

In this randomized placebo-controlled trial performed in 126 critically ill patients with sepsis, large-dose vitamin D administration did not reduce the length of ICU stay, length of hospital stay, days on mechanical ventilation or vasopressor, and 90-day mortality.

We failed to find any significant difference in the length of ICU stay in both intention to treat the population as well as the population with severe vitamin D deficiency (vitamin $D<12 \mathrm{ng} / \mathrm{mL}$ ). Although the median ICU stay in the vitamin D group was shorter by a day than the placebo group, it was statistically and perhaps clinically insignificant. We were unable to demonstrate any significant difference between the two groups with regard to secondary outcomes, like the length of hospital stay, 90-day mortality, duration of mechanical ventilation, and duration of vasopressor use. However, a trend toward reduced 90 -day mortality was observed in the vitamin D arm in the subgroup with severe vitamin D deficiency.

The findings of our study are very much similar to previous large RCTs on vitamin D supplementation in critically ill patients. In one of the largest trials (VITdAL-ICU) exploring the role of vitamin D in 492 critically ill adult patients with vitamin D deficiency $(<20 \mathrm{ng} / \mathrm{mL})$, Amrein et al. failed to find any difference in hospital length of stay, hospital mortality, or 6-month mortality. ${ }^{7}$ Similar results were also 
Table 1: Demographic and baseline characteristics of the patients

\begin{tabular}{|c|c|c|c|}
\hline Parameters & $\begin{array}{c}\text { Vitamin D3 } \\
\quad(n=63)\end{array}$ & $\begin{array}{l}\text { Placebo } \\
(n=63)\end{array}$ & $\begin{array}{c}\text { Significance } \\
(p \text { value })\end{array}$ \\
\hline Age $($ mean $\pm S D)$ & $41.95 \pm 19.42$ & $44.37 \pm 16.98$ & $0.336^{1}$ \\
\hline Female [number (\%)] & $34(53.97)$ & $30(47.62)$ & $0.593^{2}$ \\
\hline Weight (mean \pm SD) & $71.95 \pm 15.18$ & $69.40 \pm 16.43$ & $0.171^{1}$ \\
\hline Height (mean \pm SD) & $157.18 \pm 2.99$ & $158.89 \pm 4.06$ & $0.265^{1}$ \\
\hline $\mathrm{BMI}($ mean $\pm \mathrm{SD})$ & $29.12 \pm 6.04$ & $27.40 \pm 6.09$ & $0.114^{1}$ \\
\hline \multicolumn{4}{|l|}{ Cause of sepsis [number (\%)] } \\
\hline HAP & $15(23.81)$ & $11(17.46)$ & $0.51^{2}$ \\
\hline Urosepsis & $3(4.76)$ & $7(11.11)$ & $0.323^{2}$ \\
\hline Puerperal sepsis & $4(6.35)$ & $6(9.52)$ & $0.744^{2}$ \\
\hline Abdominal sepsis & $13(20.63)$ & $14(22.22)$ & $1.0^{2}$ \\
\hline CAP & 9 (14.29) & $7(11.11)$ & $0.79^{2}$ \\
\hline Skin and soft tissue infection & $7(11.11)$ & $4(6.35)$ & $0.53^{2}$ \\
\hline Acute febrile illness & $1(1.59)$ & $0(0)$ & $1.0^{2}$ \\
\hline Fournier's gangrene & $1(1.59)$ & $0(0)$ & $1.0^{2}$ \\
\hline Tropical fever & $5(7.94)$ & $8(12.70)$ & $0.56^{2}$ \\
\hline Mediastinitis & $1(1.59)$ & $0(0)$ & $1.0^{2}$ \\
\hline Meningitis & $1(1.59)$ & $1(1.59)$ & $1.0^{2}$ \\
\hline Pyopericardium & $1(1.59)$ & $0(0)$ & $1.0^{2}$ \\
\hline Empyema & $1(1.59)$ & $1(1.59)$ & $1.0^{2}$ \\
\hline Bone and joint infection & $1(1.59)$ & 3 & $0.619^{2}$ \\
\hline Infective endocarditis & $0(0)$ & $1(1.59)$ & $1.0^{2}$ \\
\hline Presence of shock [number (\%)] & $39(61.9)$ & $38(60.32)$ & $1.0^{2}$ \\
\hline Chronic pulmonary diseases [number (\%)] & $18(28.57)$ & $20(31.74)$ & $0.846^{2}$ \\
\hline Chronic cardiac diseases [number (\%)] & $22(34.92)$ & $22(34.92)$ & $1.0^{2}$ \\
\hline
\end{tabular}

${ }^{1}$ Mann-Whitney test; ${ }^{2}$ Fisher's exact test

Table 2: Outcome parameters in the total study population

\begin{tabular}{|c|c|c|c|c|}
\hline Outcome parameters & $\operatorname{Vitamin} D(n=63)$ & Placebo $(n=63)$ & $p$ value & $H R(95 \% C l)$ \\
\hline Length of ICU stay [median (range)] & $8(3-32)$ & $9(2-72)$ & $0.32^{1}$ & \\
\hline 90 days mortality [number (\%)] & $23(35.94)$ & $30(46.88)$ & $0.291^{3}$ & $0.717(0.416-1.238)$ \\
\hline Length of hospital stay [median (range)] & $12(3-56)$ & $12(3-72)$ & $0.33^{1}$ & \\
\hline Duration of vasopressors [median (range)] & $4(0-20)$ & $3(0-23)$ & $0.84^{1}$ & - \\
\hline Duration of mechanical ventilation [median (range)] & $5(0-25)$ & $7(0-68)$ & $0.23^{1}$ & \\
\hline Tracheostomy [number (\%)] & $22(34.92)$ & $25(39.68)$ & $0.71^{2}$ & \\
\hline Supplemental calcium [number (\%)] & $20(31.75)$ & $25(39.68)$ & $0.46^{2}$ & \\
\hline
\end{tabular}

${ }^{1}$ Mann-Whitney test; ${ }^{2}$ Fisher's exact test; ${ }^{3}$ Log-rank test

found in the VIOLET trial performed by the PETAL Clinical Trials Network group. ${ }^{8}$ The study was halted after the first interim analysis for futility. They were unable to detect any difference in hospital mortality in the 1,360 patients recruited. However, both the VITdALICU and VIOLET trials had recruited heterogeneous ICU populations while we recruited only sepsis patients as we thought that the immunomodulatory role of vitamin D would be more significant, and thereby more beneficial in patients with sepsis. In a prior RCT conducted in critically ill sepsis patients, administration of singledose intravenous calcitriol $2 \mu \mathrm{g}$ had mixed effects on markers of inflammation and innate immunity. ${ }^{9}$ However, it was a small study conducted in 67 patients only and calcitriol was not administered early. Moreover, it was primarily a physiological study aimed at finding the differences in biomarkers rather than clinical outcomes. In the current study, vitamin D was administered early through the enteral route, and only clinical endpoints were assessed.

The patient population in the present study was significantly sicker than the previous studies. In the present study, $62 \%$ of patients in the study group and $60 \%$ in the control group were in shock at presentation (55 and 53\%, respectively, in study and control groups in the VITdAL-ICU trial and 31.4 and $32.8 \%$, respectively, in the VIOLET trial). The median SOFA scores in our study were 8 and 10 for the study and control groups, respectively. The VIOLET trial on the contrary had median SOFA scores of 5.6 and 5.4 in the study and 

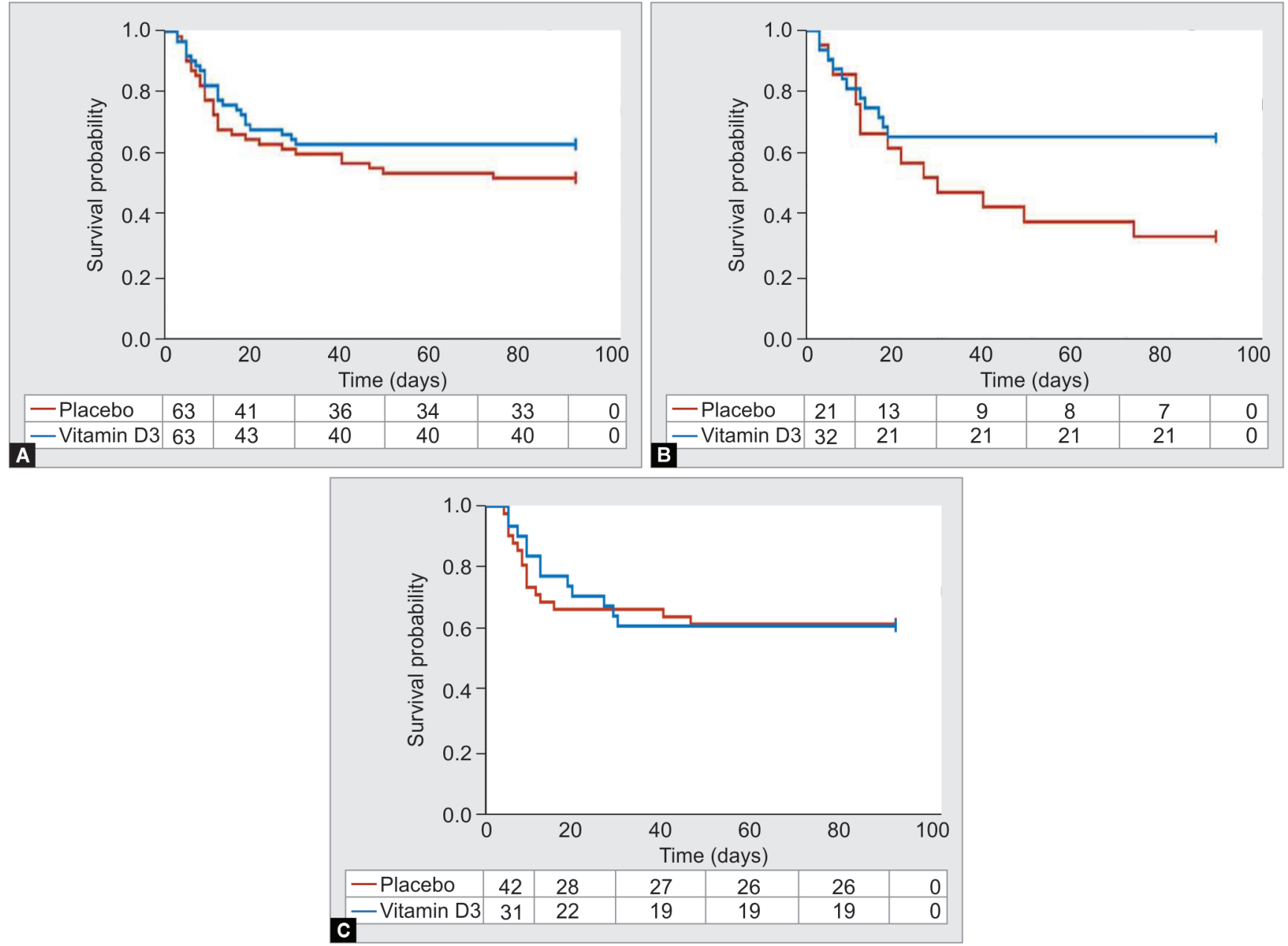

Figs $1 \mathrm{~A}$ to $\mathrm{C}$ : Kaplan-Meier curve of 90 -day survival; $(\mathrm{A})$ in all patients; $(\mathrm{B})$ in patients with vitamin $\mathrm{D}<12 \mathrm{ng} / \mathrm{mL}$; and $(\mathrm{C})$ in patients with vitamin $\mathrm{D}>12 \mathrm{ng} / \mathrm{mL}$

Table 3: Outcome parameters in subgroups with or without severe vitamin D deficiency

\begin{tabular}{|c|c|c|c|c|}
\hline \multicolumn{5}{|c|}{ Outcome parameters in patients with severe vitamin D deficiency (Vitamin $D<12 \mathrm{ng} / \mathrm{mL}$ ) } \\
\hline Outcome parameters & Vitamin $D(n=32)$ & Placebo $(n=21)$ & $p$ value & $H R(95 \% \mathrm{Cl})$ \\
\hline Length of ICU stay [median (range)] & $8(3-27)$ & $12(2-72)$ & $0.18^{1}$ & \\
\hline 90 days mortality [number (\%)] & $11(34.38)$ & $14(66.66)$ & $0.087^{3}$ & $0.449(0.198-1.017)$ \\
\hline Length of hospital stay [median (range)] & $12(3-45)$ & $12(3-72)$ & $0.36^{1}$ & \\
\hline Duration of vasopressors [median (range)] & $4(0-20)$ & $5(0-23)$ & $0.28^{1}$ & \\
\hline Duration of Mechanical ventilation [median (range)] & $6(0-24)$ & $11(0-68)$ & $0.058^{1}$ & \\
\hline Tracheostomy [number (\%)] & $9(28.13)$ & $12(57.14)$ & $0.047^{2}$ & \\
\hline Supplemental calcium [number (\%)] & $14(43.75)$ & $10(47.62)$ & $1.0^{2}$ & \\
\hline \multicolumn{5}{|c|}{ Outcome parameters in patients without severe vitamin D deficiency (vitamin $D \geq 12 \mathrm{ng} / \mathrm{mL}$ ) } \\
\hline Outcome parameters & Vitamin $D(n=31)$ & Placebo $(n=42)$ & pvalue & $H R(95 \% C l)$ \\
\hline Length of ICU stay [median (range)] & $7(3-32)$ & $9(3-50)$ & $0.76^{1}$ & \\
\hline 90 days mortality [number (\%)] & $12(38.71)$ & $16(38.10)$ & $0.95^{3}$ & $0.951(0.446-2.027)$ \\
\hline Length of hospital stay [median (range)] & $10(5-56)$ & $12(4-67)$ & $0.61^{1}$ & \\
\hline Duration of vasopressors [median (range)] & $4(0-19)$ & $3(0-20)$ & $0.82^{1}$ & \\
\hline Duration of mechanical ventilation [median (range)] & $5(0-25)$ & $6(0-44)$ & $0.75^{1}$ & \\
\hline Tracheostomy [number (\%)] & $13(41.94)$ & $13(30.95)$ & $0.46^{2}$ & \\
\hline Supplemental calcium [number (\%)] & $6(19.36)$ & $15(35.71)$ & $0.191^{2}$ & \\
\hline
\end{tabular}

${ }^{1}$ Mann-Whitney test; ${ }^{2}$ Fisher's exact test; ${ }^{3}$ Log-rank test 
Table 4: Change of parameters from day 1 to day 5

\begin{tabular}{|c|c|c|c|c|c|c|c|c|}
\hline \multirow[b]{2}{*}{ Parameters } & \multicolumn{3}{|c|}{ Day 1} & \multicolumn{3}{|c|}{ Day 5} & \multicolumn{2}{|c|}{$\%$ change from D1 to D5 [median (range); $p$ value ${ }^{2}$ ] } \\
\hline & $\begin{array}{l}\text { Vitamin D } \\
(n=63)\end{array}$ & $\begin{array}{l}\text { Placebo } \\
(n=63)\end{array}$ & p value ${ }^{1}$ & $\begin{array}{l}\text { Vitamin D } \\
(n=63)\end{array}$ & $\begin{array}{l}\text { Placebo } \\
(n=63)\end{array}$ & p value & $\begin{array}{c}\text { Vitamin D } \\
(n=63)\end{array}$ & $\begin{array}{l}\text { Placebo } \\
(n=63)\end{array}$ \\
\hline $\begin{array}{l}\text { SOFA } \\
\text { [median } \\
\text { (range)] }\end{array}$ & $8(2-20)$ & $10(1-21)$ & 0.93 & $6(0-20)$ & $7(0-21)$ & 0.80 & $-33.33(-100,200) ; 0.17$ & $-20(-100,1200) ; 0.09$ \\
\hline $\begin{array}{l}\text { Vitamin D } \\
(\mathrm{ng} / \mathrm{mL})\end{array}$ & $12.05 \pm 6.19$ & $15.47 \pm 10.58$ & 0.096 & $17.73 \pm 7.57$ & $16.4 \pm 13.47$ & 0.03 & $\begin{array}{l}50.79(-32.42,309.38) \\
<0.0000\end{array}$ & $\begin{array}{l}5.26(-91.07,116.07) \\
0.11\end{array}$ \\
\hline $\begin{array}{l}\text { lonized } \\
\text { Calcium } \\
\text { (mmol/L) }\end{array}$ & $1.11 \pm 0.15$ & $1.18 \pm 0.11$ & 0.0001 & $1.23 \pm 0.18$ & $1.26 \pm 0.29$ & 0.95 & $\begin{array}{l}9.09(-18.18,120.0) \\
<0.0000\end{array}$ & $\begin{array}{l}7.7(-34.55,162.5) \\
0.06\end{array}$ \\
\hline $\begin{array}{l}\text { Procalcitonin } \\
(\mathrm{ng} / \mathrm{mL})\end{array}$ & $5.79 \pm 5.31$ & $5.61 \pm 5.82$ & 0.66 & $4.72 \pm 6.31$ & $5.09 \pm 6.13$ & 0.66 & $\begin{array}{l}-26.83(-98.75,2900.0) ; \\
0.14\end{array}$ & $\begin{array}{l}-22.22(-98.28,1700.0) \\
0.43\end{array}$ \\
\hline
\end{tabular}

${ }^{1}$ Mann-Whitney test; ${ }^{2}$ Paired $t$-test

control groups, respectively. This is reflected in the higher mortality that was noted in both the treatment and placebo arm (35.94 and $46.88 \%$, respectively) in the present study, compared to both the arms of the VIOLET trial ( 23.5 and $20.6 \%$, respectively). It is possible that vitamin $\mathrm{D}$ administration in early sepsis, before the onset of organ dysfunction, may yield more favorable outcomes. It was therefore planned to recruit patients in early sepsis by aiming for early randomization and drug or placebo administration. However, many patients in the current study had organ dysfunction at presentation which could have influenced the efficacy of vitamin D.

In the current study, vitamin D levels in the intervention arm appeared to be significantly lower than in other studies. In the VITdAL-ICU trial, the mean day 3 vitamin D level was 33.5 (SD 18.7) $\mathrm{ng} / \mathrm{mL}$, compared to the median day 5 level $17.73 \pm 7.57 \mathrm{ng} / \mathrm{mL}$ in the current study. Despite a statistically significant percentile increase reported from day 1 to day 5 value in the intervention group, vitamin D level was still low. This could be due to poor absorption as a majority of the patients were in shock with organ dysfunction at presentation. Severe ongoing vitamin D deficiency in the recruited patients and reduced efficiency of the preparation of vitamin D used could be other contributory factors. Moreover, failure of augmentation of vitamin D levels could have affected the study outcomes. A mild nonsignificant increase in vitamin D level in the control group may be considered a chance phenomenon.

Unlike the previous studies, we did not screen our patients for a vitamin D level and enrolled patients into the study irrespective of their baseline vitamin $D$ levels. There were many reasons for this. Firstly, a previous study in our center reported that $75 \%$ of the patients were deficient and had vitamin D levels $<30 \mathrm{ng} / \mathrm{mL} .{ }^{10}$ This is similar to other studies performed on critically ill patients. ${ }^{5,6,10}$ This led us to conclude that measuring vitamin D levels before supplementation would not translate to pragmatic ICU practice. Secondly, there have been reports in the literature that the serum vitamin D levels are subject to diurnal variations and a single random value may not be representative of the actual picture. ${ }^{11}$ Thirdly, we have no data on optimum levels of vitamin D for critically ill patients in the Indian population. ${ }^{12}$ Besides, we did not want to miss out the patients who might go on to develop a deficiency in the course of their ICU stay and hence might be missed by a screening vitamin D level. We, however, performed a subgroup analysis of the most severely deficient patients (vitamin D levels $<12 \mathrm{ng} / \mathrm{mL}$ ) and observed a trend toward reduced 90 -day mortality with vitamin D supplementation in this subpopulation, but failed to find any significant difference in other outcomes.

The immunomodulatory role of vitamin D in sepsis is not direct but rather an indirect effect brought about by genomic modulation. ${ }^{2}$ As such it takes at least 48 hours for the absorption, metabolism, and initiation of these cellular-level effects. Therefore, maximum benefit from supplementation could only be realized if we administer it early. We aimed to randomize our patients within 24 hours of hospital presentation with the administration of drug or placebo within the subsequent 2 hours. We exceeded this time limit in only one patient in the control group. The median duration from hospital admission to time of randomization in our study was 6 hours. The VIOLET trial also enrolled patients early in their ICU stay but in the VITdAL-ICU trial, the mean duration before study enrolment was as long as 3 days.

The safety and efficacy of a single large bolus dose of vitamin D have been extensively studied. Kearns et al. performed a metaanalysis and concluded that large single dosages of vitamin D consistently increased the serum values to optimum levels. ${ }^{13}$ Amrein et al. found that a large single dose of $540,000 \mathrm{U}$ of vitamin D given to vitamin $D$ deficient patients was able to increase the levels to normal range within 2 days and was not associated with any adverse effects, like hypercalcemia, hyperphosphatemia, or calciuria. ${ }^{14}$ In our study, although the baseline vitamin D levels were not different, at day 5 , there was a significant difference between the treatment and control groups $(p=0.03)$. There was a median change of $50.71 \%$ from baseline vitamin D levels in the study group by day 5 . An increase in ionized calcium levels was observed in both treatment and control groups, perhaps due to immobilization and bone resorption as are commonly seen in critically ill patients. However, none of the patients developed symptomatic hyperkalemia or hyperphosphatemia requiring treatment in the 90 days follow-up.

Since cutaneous vitamin D synthesis is sunlight dependent, it is often concluded that people with tropical sun exposure have higher levels of this hormone by default. This, however, may be a gross oversimplification as evidenced by the high levels of vitamin D deficiency in tropical countries, like Brazil and India. ${ }^{15,16}$ This underscores the importance of exploring the possible therapeutic role of an economical therapy like vitamin D supplementation.

Although a large number of studies have observed deficiency of vitamin D in critically ill patients, most studies including this 
have not been able to report any benefit on supplementation of vitamin D. ${ }^{15}$ This could be due to many reasons. Firstly, we could be looking at the wrong endpoint. Length of ICU stay was the primary outcome in the current study as well as in the VITdAL-ICU trial, whereas in the VIOLET trial 90-day mortality was the primary outcome. However, as Martucci et al. stated in their post hoc analysis of the VITdAL-ICU trial, the pleiotropic effects of vitamin $D$ are brought about by genetic modulation and may take up to 7 days to come into effect. ${ }^{16}$ Thus any patient in the study group with a length of ICU stay less than 7 days might not have derived any benefits from vitamin $D$ administration. In the study group, we had 12 such patients accounting for $19 \%$ of the treatment arm population. Secondly, low vitamin D levels may be an associated finding rather than a cause of adverse outcomes, and hence treating it might not lead to better patient outcomes. Considering the plethora of preclinical data available on the beneficial immunomodulatory role of vitamin $D$, we feel that we are probably missing some key ingredient or practice that will translate these theoretical benefits to positive clinical outcomes. Larger, perhaps methodologically modified studies may in fact shed further light in this area. ${ }^{17}$

\section{Strengths and Limitations}

There are various strengths of our study. Firstly, to the best of our knowledge, this was the first RCT exploring the possible benefits of vitamin D supplementation in septic ICU patients. Our treatment and placebo groups were well matched at baseline with adequate blinding of personnel. There was no data loss to follow-up. To prevent co-interventions, none of the study participants received supplemental vitamin D during the ICU stay. We were, however, not able to extend this stipulation for the duration of the entire follow-up. In post-ICU discharge, $13 \%$ of the participants in the study group and $10 \%$ of the participants in the placebo group received vitamin D. Administration of supplemental calcium, however, was left to the discretion of the treating physician, and $20 \%$ of the treatment group and $25 \%$ of the placebo group received supplemental calcium.

There were some limitations in our study. We did not obtain the parathyroid hormone level or any objective assessment of urinary calcium excretion. Physical outcome parameters like handgrip and muscle strength were not assessed. We had decided on 90-day mortality as one of our long-term secondary outcomes. Considering the immunomodulatory role of vitamin D and its possible role in preventing post-intensive care syndrome (PICS), mortality might have been a rather overreaching secondary outcome. Although the current study was adequately powered, it was not designed to detect mortality differences. However, a trend toward reduced 90 -day mortality in severe vitamin D deficiency $(<12 \mathrm{ng} / \mathrm{mL})$ subgroup seems encouraging and suggests the need for a larger $\mathrm{RCT}$ in these groups of patients.

\section{CONCLUSION}

To conclude, vitamin D deficiency is prevalent in critically ill patients with sepsis. However, large-dose vitamin D supplementation within 24 hours of admission in these patients does not decrease the length of ICU stay or improve other clinical outcomes.

\section{Acknowledgment}

The authors acknowledge the contribution of Dr Esha Baidya Kayal, $\mathrm{PhD}$, for performing statistical analysis for this study.

\section{Ethics Approval and Consent to Participate}

The Ethics committee of the All India Institute of Medical Sciences, New Delhi, approved the study, vide letter number IECPG239/28.09.2018, RT-39/30.08.2018, and consent was obtained from all the patients or their legally acceptable representatives.

\section{Author Contribution}

Dalim Kumar Baidya and Rajeshwari Subramaniam planned in the concept and design of the study. Amrita Bhattacharyya, Praveen Aggarwal, Dalim Kumar Baidya, and Naveet Wig contributed to the data acquisition. Amrita Bhattacharyya did the data tabulation and manuscript writing. Dalim Kumar Baidya and Rajeshwari Subramaniam did the manuscript editing. All the authors reviewed and approved the final manuscript.

\section{OrCID}

Amrita Bhattacharyya 이 https://orcid.org/0000-0002-3019-9925

Rajeshwari Subramaniam @ https://orcid.org/0000-0002-3830-5278

Dalim K Baidya @ https://orcid.org/0000-0001-7811-7039

Praveen Aggarwal (1) https://orcid.org/0000-0002-4611-5458

Naveet Wig @ i https://orcid.org/0000-0002-6603-601X

\section{References}

1. Bikle D. Nonclassic actions of vitamin D. J Clin Endocrinol Metab 2009;94(1):26-34. DOI: 10.1210/jc.2008-1454.

2. Holick MF. Vitamin D deficiency. N Engl J Med 2007;357(3):266-281. DOI: 10.1056/NEJMra070553.

3. Bartley J. Vitamin D: emerging roles in infection and immunity. Expert Rev Anti Infect Ther 2010;8(12):1359-1369. DOI: 10.1586/eri.10.102.

4. Zhang Y-P, Wan Y-D, Sun T-W, Kan Q-C, Wang L-X. Association between vitamin $D$ deficiency and mortality in critically ill adult patients: a meta-analysis of cohort studies. Crit Care 2014;18(6):684. DOI: 10.1186/ s13054-014-0684-9.

5. Singer M, Deutschman CS, Seymour CW, Shankar-Hari M, Annane D, Bauer $M$, et al. The third international consensus definitions for sepsis and septic shock (Sepsis-3). JAMA 2016;315(8):801-810. DOI: 10.1001/ jama.2016.0287.

6. Sinha H, Maitra S, Anand RK, Aggarwal R, Rewari V, Subramaniam R, et al. Epidemiology and Prognostic Utility of Cellular Components of Hematological System in Sepsis. Indian J Crit Care Med 2021;25(6):660-667. DOI: 10.5005/jp-journals-10071-23874.

7. Amrein K, Schnedl C, Holl A, Riedl R, Christopher KB, Pachler C, et al. Effect of high-dose vitamin D3 on hospital length of stay in critically ill patients with vitamin D deficiency: the VITdAL-ICU randomized clinical trial. JAMA 2014;312(15):1520-1530. DOI: 10.1001/jama.2014.13204.

8. Ginde AA, Brower RG, Caterino JM, Finck L, Banner-Goodspeed VM, Grissom CK, et al. Early high-dose vitamin D3 for critically ill, vitamin D-deficient patients. N Engl J Med 2019;381(26):2529-2540. DOI: 10.1056/NEJMoa1911124.

9. Leaf DE, Raed A, Donnino MW, Ginde AA, Waikar SS. Randomized controlled trial of calcitriol in severe sepsis. Am J Respir Crit Care Med 2014;190(5):533-541. DOI: 10.1164/rccm.201405-0988OC.

10. Yadav S, Joshi P, Dahiya U, Baidya DK, Goswami R, Guleria R, et al. Admission vitamin $D$ status does not predict outcome of critically ill patients on mechanical ventilation: an observational pilot study. Indian J Anaesth 2018;62(1):47-52. DOI: 10.4103/ija.IJA_531_17.

11. Venkatesh B, Davidson B, Robinson K, Pascoe R, Appleton C, Jones M. Do random estimations of vitamin D3 and parathyroid hormone reflect the $24-\mathrm{h}$ profile in the critically ill? Intensive Care Med 2012;38(1):177-179. DOI: 10.1007/s00134-011-2415-x.

12. NairP,Venkatesh B,Center JR. Vitamin D deficiency and supplementation in critical illness-the known knowns and known unknowns. Crit Care 2018;22(1):276. DOI: 10.1186/s13054-018-2185-8. 
13. Malihi Z, Wu Z, Lawes CMM, Scragg R. Adverse events from large dose vitamin $D$ supplementation taken for one year or longer. J Steroid Biochem Mol Biol 2019;188:29-37. DOI: 10.1016/j.jsbmb.2018.12.002.

14. Amrein K, Sourij H, Wagner G, Holl A, Pieber TR, Smolle KH, et al. Shortterm effects of high-dose oral vitamin D3 in critically ill vitamin $D$ deficient patients: a randomized, double-blind, placebo-controlled pilot study. Crit Care 2011;15(2):R104. DOI: 10.1186/cc10120.

15. de Haan K, Groeneveld ABJ, de Geus HRH, Egal M, Struijs A. Vitamin D deficiency as a risk factor for infection, sepsis and mortality in the critically ill: systematic review and meta-analysis. Crit Care 2014;18(6):660. DOI: 10.1186/s13054-014-0660-4.
16. Martucci G, McNally D, Parekh D, Zajic P, Tuzzolino F, Arcadipane A et al. Trying to identify who may benefit most from future vitamin $D$ intervention trials: a post hoc analysis from the VITDAL-ICU study excluding the early deaths. Crit Care 2019;23(1):200. DOI: 10.1186/ s13054-019-2472-z.

17. Amrein K, Parekh D, Westphal S, Preiser J-C, Berghold A, Riedl R, et al. Effect of high-dose vitamin D3 on 28-day mortality in adult critically ill patients with severe vitamin D deficiency: a study protocol of a multicentre, placebo-controlled double-blind phase III RCT (the VITDALIZE study). BMJ Open 2019;9(11):e031083. DOI: 10.1136/ bmjopen-2019-031083. 